\title{
A Safety Test for Ocular Phototoxicity in the Rabbit After Short-term Exposure to Strong Light
}

\author{
HYEJI PARK ${ }^{1,2^{*}}$, KWANGSIK JANG $^{1,2^{*}}$, YESOL JO ${ }^{1,2}$, KYUNG MI SHIM $^{1,2}$, \\ CHUNSIK BAE ${ }^{1,2}$, SEONG SOO KANG ${ }^{1,2}$ and SE EUN KIM ${ }^{1,2}$ \\ ${ }^{1}$ Department of Veterinary Surgery, College of Veterinary Medicine and BK21 FOUR Program, \\ Chonnam National University, Gwangju, Republic of Korea; \\ ${ }^{2}$ Biomaterial R\&BD Center, Chonnam National University, Gwangju, Republic of Korea
}

\begin{abstract}
Background/Aim: Self-defense products that use high-intensity light are being developed. The intense light generated by the high-power light-emitting diodes (LEDs) of such self-defense products causes temporary blindness. However, few studies have been conducted on the visual safety of their devices. We, therefore, evaluated the effects of strong light of a short duration on the eyes of rabbits in this study. Materials and Methods: The right eyes of 15 rabbits were irradiated for $5 \mathrm{~s}$ with a lighting device $(25 \mathrm{~W}, 150 \mathrm{~lm} / \mathrm{W}$ at $700 \mathrm{~mA}$ LED) and four eyes of two rabbits were nonirradiated as controls. Changes in the eye structure and function were evaluated before, and immediately, $30 \mathrm{~min}, 1 \mathrm{~h}$, 24 h, 7 days and 14 days after light irradiation by full-field electroretinogram (ERG), slit-lamp biomicroscopy, and retinal camera. The thickness of the outer nuclear layer of the retina tissue was measured, and histopathological signs of retinal damage were analyzed. Results: The ERG results showed that night vision was not affected. In day vision, the ERG waveform was temporarily affected immediately after light irradiation; however, it recovered within $24 \mathrm{~h}$. No histopathological signs of damage were observed. Conclusion:
\end{abstract}

This article is freely accessible online.

*These Authors contributed equally to the study.

Correspondence to: Se Eun Kim, DVM, Ph.D., College of Veterinary Medicine, Chonnam National University, 77, Yongbongro, Buk-gu, Gwangju, 61186, Republic of Korea. Tel: +82 625302812, Fax: +82 625302809, e-mail: ksevet@jnu.ac.kr and Seong Soo Kang, DVM, Ph.D., College of Veterinary Medicine, Chonnam National University, 77, Yongbong-ro, Buk-gu, Gwangju, 61186, Republic of Korea. Tel: +82 625302877, Fax: +82 625302809, e-mail: vetkang@chonnam.ac.kr

Key Words: Self-defense product, light exposure, phototoxicity, electroretinogram, rabbit.
Application of high-power LED light with short duration as used for self-defense was found to cause temporary phototoxicity, but safety was confirmed as vision recovered within $24 \mathrm{~h}$.

Recently, self-defense products have been developed which use intense LED light to blind an attacker temporarily. Therefore, research on the safety of such devices also needs to be conducted. Several studies have reported retinal damage caused by various light sources, such as home lights using light-emitting diodes (LEDs) and ophthalmic surgical microscopes (1-4). However, no studies have been conducted to test the time needed for vision recovery and the extent of retinal damage after a short duration $(5 \mathrm{~s})$ of exposure to light bright enough to be used for self-defense.

The mechanisms of damage to the retina by light can be divided into mechanical, thermal, and chemical (5-7). Mechanical damage is caused by shock waves when the eye is exposed to light for a short duration, from nanoseconds to picoseconds, with intensity ranging from megawatts to terawatts per $\mathrm{cm}^{2}$. Thermal damage occurs when the eye is exposed to light with increasing kinetic energy that can cause an increase in the temperature around the retina by more than $10^{\circ} \mathrm{C}(6,7)$. Sources of light that can cause mechanical and thermal damage are rarely used. However, chemical damage is a major result of light-induced phototoxicity. When incident radiation has a wavelength that falls within the high-energy portion of the visible spectrum, different interactions occur between the radiant energy and biological molecules. The excited electrons dissipate extra energy to return to the ground state. In the process, reactive oxygen species, such as hydrogen peroxide, singlet oxygen, hydroxyl radicals, and superoxide radicals, are formed in retinal molecules, resulting in photoreceptor apoptosis and damage to retinal tissue $(8,9)$.

There are various methods for evaluating phototoxicity. Krigel et al. conducted a study using electroretinography (ERG) as an evaluation method after light exposure (3). Lee et al. evaluated 
phototoxicity with ERG and transmission electron microscopy (4). ERG provides an objective method for separately assessing impairment in rod and cone functions in degenerative disorders and pharmacological studies. When testing dark-adapted eyes by ERG, rod cells mainly contribute to the results. Using various settings of ERG, different degrees of cone function can be assessed. Saenz-de-Viteri et al. also measured the thickness of the outer nuclear layer (ONL) of the retina and neurosensory retina using histological analysis (10). They counted the number of photoreceptors on hematoxylin-eosin (H\&E)-stained sections after the induction of phototoxicity. A significant decrease in the thickness of the ONL and neurosensory retina was observed. The photoreceptor counts showed no significant differences, but an increase in vacuolization within the outer segments of the photoreceptors was observed.

This study used short-term bright light from a self-defense product designed to cause temporary blindness using a highpower LED light source. The changes within rabbit eyes were quantitatively evaluated for up to 2 weeks after irradiation. Structural damage was evaluated using slit-lamp biomicroscopy and a retinal camera. Functional damage was assessed with ERG, which investigated the recovery time, and color and contrast recognition. Histological examination was performed to determine light-induced histological changes within the retinal tissue. Through these examinations, ocular phototoxicity after exposure to light from a self-defense product was quantitatively evaluated. This study assessed how long a self-defense product affects normal vision and whether it causes any other damage after temporary blindness.

\section{Materials and Methods}

In vivo studies of the effects of light irradiation. This study used 17 male New Zealand White rabbits (weight, 2.6-3.3 kg; age, 13-16 weeks; Damool Science, Daejeon, Republic of Korea). The lightirradiated groups (with five animals each) were divided into three based on the day of sacrifice after irradiation: Groups were sacrificed $24 \mathrm{~h}, 7$ and 14 days after light irradiation, respectively. The right eyes of 15 rabbits comprised the three light-irradiated groups, and a total of four eyes of two rabbits comprised the control group. All experimental procedures were submitted and approved by the Institutional Animal Care and Use Committee of Chonnam National University (Authorization number: CNU IACUC-YB-2020-34).

Light source. LUHERO ${ }^{\circledR}$ (Newseogwang Co., Gwangju, Korea), a self-defense product made with high-output light sources (four LEDs emitting a total of $25 \mathrm{~W}, 150 \mathrm{~lm} / \mathrm{W}$ at $700 \mathrm{~mA} \mathrm{LED)} \mathrm{and} \mathrm{a}$ narrow-angle lens that collects light was used. The lighting device was directed toward the rabbit cornea at $1 \mathrm{~cm}$ from the corneal surface, and the eye was irradiated for $5 \mathrm{~s}$.

Ophthalmic evaluations. All animals were examined by slit-lamp biomicroscopy (SLM-3ER-E Digital Slit Lamp; Kanghua Ruiming Science \& Technology Co., Ltd., Chongqing, PR China) and a retinal camera (Horus DEC-200; MiiS, Hsinchu, Taiwan, ROC) before light irradiation and at sacrifice. The slit-lamp was used to evaluate the conjunctiva, cornea, anterior chamber, light reflex, iris, and lens. The retinal camera was used to assess the fundus, including the optic disc and retinal blood vessels. Full-field ERG (RETevet $^{\mathrm{TM}}$; LKC Technologies Inc., Gaithersburg, MD, USA) was performed before, and immediately, $30 \mathrm{~min}, 1 \mathrm{~h}, 24 \mathrm{~h}, 7$ days, and 14 days after light irradiation. For the dark-adapted ERG test, dark adaption was induced at least $50 \mathrm{~min}$ before testing. The rabbits were anesthetized with an intramuscular injection of $5 \mathrm{mg} / \mathrm{kg}$ xylazine hydrochloride (Rompun ${ }^{\circledR}$; Bayer Korea Ltd., Seoul, Republic of Korea) and $20 \mathrm{mg} / \mathrm{kg}$ ketamine hydrochloride (Yuhan Ketamine $50 \mathrm{Inj}^{\circledR}$; Yuhan Co., Seoul, Republic of Korea). The pupil was dilated with $0.5 \%$ tropicamide/phenylephrine eye drops (Mydrin ${ }^{\circledR}-\mathrm{P}$; Santen Pharmaceutical Co., Osaka, Japan). The cornea was anesthetized with $0.5 \%$ proparacaine HCL eye drops (Alcaine ${ }^{\circledR}$ eye drops $0.5 \%$; Alcon Laboratories Inc., Fort Worth, TX, USA), and ERG electrodes were placed as follows: Jet contact lenstype electrode with $2 \%$ hydroxypropyl methylcellulose $\left(\right.$ Hycell ${ }^{\circledR}$, Samil Pharm Co., Seoul, Republic of Korea) on the cornea (active electrode), needle electrode ipsilaterally between the caudal and the lateral canthi (reference electrode), and gold-dome electrode in the mouth (ground electrode). In the dark-adapted state, scotopic tests were performed, and then photopic tests were performed after $5 \mathrm{~min}$ of light adaptation. After removing the ERG lens-type active electrode, the eye was irradiated for $5 \mathrm{~s}$ with bright light from the self-defense device at $1 \mathrm{~cm}$ from the corneal surface. The ERG electrodes were replaced, and photopic tests were performed immediately, and $30 \mathrm{~min}$, and $1 \mathrm{~h}$ after light irradiation. The amplitudes of a- and b-waves and the implicit durations of the a- and b-waves were analyzed as parameters. The results are presented in microvolts for amplitudes and milliseconds for implicit times. All the parameter values before and after light irradiation were compared.

ERG was performed according to the research protocols set for testing rabbits in a machine. The stimuli were 2.5-6.0 times brighter than that recommended in the dog, cat and primate protocol by LKC Technologies Inc. In this protocol, six responses are recorded. The set values were as follows: (a) Dark-adapted test 1: scotopic rod response, flash $=0.060 \mathrm{~cd} \cdot \mathrm{s} / \mathrm{m}^{2}$ at a frequency of $0.5 \mathrm{~Hz}$, of ideal white light with Commission Internationale de l'Eclairage coordinates $(0.33,0.33)$ (hereinafter referred to as white light), background luminance $=0.0 \mathrm{~cd} / \mathrm{m}^{2}$; (b) dark-adapted test 2 : scotopic rod and cone mixed response, flash $=8.0 \mathrm{~cd} \cdot \mathrm{s} / \mathrm{m}^{2}$ at a frequency of $0.1 \mathrm{~Hz}$, white light $(0.33,0.33)$, background luminance $=0.0 \mathrm{~cd} \cdot \mathrm{s} / \mathrm{m}^{2}$; (c) dark-adapted test 3: oscillatory potentials were automatically calculated from the dark-adapted test 2 and up to five cursors were automatically placed on the peaks and troughs of the oscillatory potentials; (d) dark-adapted test 4: scotopic rod and cone mixed response to a higher intensity flash, flash $=25 \mathrm{~cd} \cdot \mathrm{s} / \mathrm{m}^{2}$ at a frequency of $0.05 \mathrm{~Hz}$, white light $(0.33,0.33)$, background luminance $=0.0$ $\mathrm{cd} / \mathrm{m}^{2}$; (e) light-adapted test 1: photopic rod and cone mixed response, flash $=8.0 \mathrm{~cd} \cdot \mathrm{s} / \mathrm{m}^{2}$ at a frequency of $2 \mathrm{~Hz}$, white light $(0.33,0.33)$, background luminance $=30 \mathrm{~cd} / \mathrm{m}^{2}$; (f) light-adapted test 2: photopic cone response, flash $=8.0 \mathrm{~cd} \cdot \mathrm{s} / \mathrm{m}^{2}$ at a frequency of 28.3 $\mathrm{Hz}$ white light $(0.33,0.33)$, background luminance $=30 \mathrm{~cd} / \mathrm{m}^{2}$.

Histological analysis. The animals were sacrificed using intravenous potassium chloride (KCl-40 ${ }^{\circledR}$ inj.; Daihan Pharmacy, Seoul, Republic of Korea) after general anesthesia, and the eyes were enucleated. The eyes were immersed in Davidson's Fixative solution (BBC Biochemical Co., Mount Vernon, WA, USA). The tissues were processed and stained with $\mathrm{H} \& \mathrm{E}$ following the conventional procedure. ONL thickness measurements were performed on the H\&E-stained sections. The ONL 

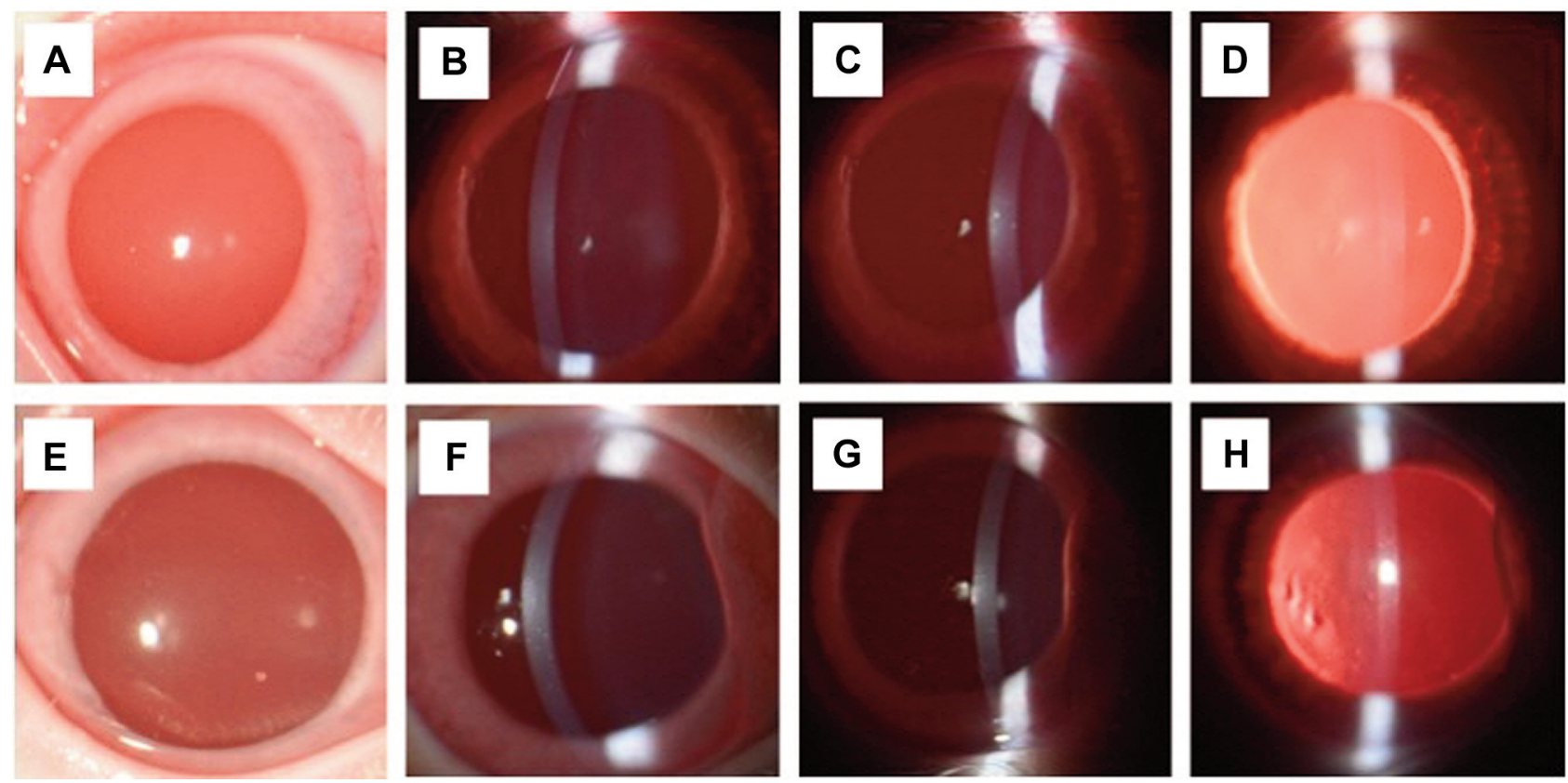

Figure 1. Slit-lamp biomicroscopy of the control and light-irradiated groups. Broad-beam illumination before (A) and after light irradiation (E). Narrow-beam $(2 \mathrm{~mm})$ optic section before $(B, C)$ and after light irradiation $(F, G)$. Retroillumination from the fundus before $(D)$ and after light irradiation (H). The cornea, iris, and anterior chamber (left side, temporal; right side, nasal) showed no abnormal findings.
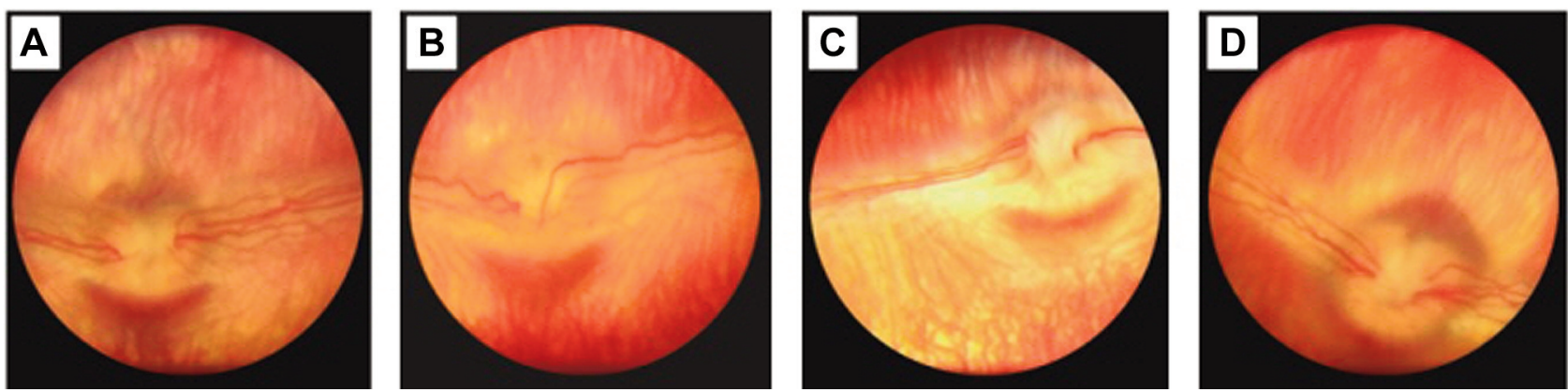

Figure 2. Photographs of the fundus in control and light-irradiated groups. Control (A), Group 1 (24 hafter light irradiation) (B), Group 2 (7 days after light irradiation) (C), and Group 3 (14 days after light irradiation) (D). No structural damage of the general fundus, including the optic disc and retinal and choroidal vasculatures, was observed after light irradiation (left side: temporal, right side: nasal).

thickness was randomly measured at four points $2,000 \mu \mathrm{m}$ from the optic nerve, and the mean values were compared.

Statistical analysis. ERG analysis was performed to compare the effects pre light irradiation with those post light irradiation quantitatively, and the ONL thickness measurements of the control and light-irradiated groups were compared. The values are presented as the mean \pm standard deviation (SD). Student's $t$-test was used to evaluate statistical significance; differences with $p<0.05$ were considered significant.

\section{Results}

Ophthalmic evaluations. The light-irradiated eyes did not have corneal edema, corneal vascularization, corneal melanosis, uveitis, or iritis (Figure 1). One animal had conjunctival hyperemia and edema in the light-irradiated eye. No structural damage to the general fundus, including the optic disc and the retinal and choroidal vasculature, was observed after light irradiation (Figure 2). 
in vivo $36: 233-240(2022)$

Table I. Results of light-adapted electroretinography before and after light exposure.

\begin{tabular}{|c|c|c|c|c|c|c|c|c|}
\hline Parameter & Test & Pre-irradiation & Immediately after & 30 min after & $1 \mathrm{~h}$ after & $24 \mathrm{~h}$ after & 7 Days after & 14 Days after \\
\hline a-Wave implicit time (ms) & 1 & $10.14 \pm 0.31$ & $9.22 \pm 0.79$ & $10.82 \pm 0.23 *$ & $11.46 \pm 0.75^{*}$ & $10.54 \pm 0.50$ & $10.02 \pm 0.17$ & $10.40 \pm 0.95$ \\
\hline \multirow[t]{2}{*}{ b-Wave implicit time (ms) } & 1 & $26.78 \pm 0.19$ & $25.1 \pm 0.23 *$ & $27.88 \pm 0.46^{*}$ & $28.18 \pm 0.22 *$ & $26.32 \pm 0.32 *$ & $25.12 \pm 0.66^{*}$ & $26.26 \pm 1.16$ \\
\hline & 2 & $24.86 \pm 0.22$ & $24.24 \pm 0.20 *$ & $25 \pm 0.33$ & $25.14 \pm 0.26$ & $25.04 \pm 0.23$ & $24.60 \pm 0.32$ & $24.84 \pm 0.45$ \\
\hline a-Wave amplitude $(\mu \mathrm{V})$ & 1 & $-8.24 \pm 0.47$ & $-6.4 \pm 0.37 *$ & $-13.04 \pm 1.76^{*}$ & $-12.96 \pm 1.98 *$ & $-9.2 \pm 1.74$ & $-8.12 \pm 1.42$ & $-9.24 \pm 2.02$ \\
\hline \multirow[t]{2}{*}{ b-Wave amplitude $(\mu \mathrm{V})$} & 1 & $117.4 \pm 7.39$ & $77.06 \pm 0.89 *$ & $149.4 \pm 7.45^{*}$ & $144.8 \pm 11.55^{*}$ & $110.6 \pm 11.86$ & $121.80 \pm 11.75$ & $127.20 \pm 19.81$ \\
\hline & 2 & $82.78 \pm 5.78$ & $72.94 \pm 2.36^{*}$ & $75.76 \pm 5.51$ & $76.1 \pm 7.28$ & $86.6 \pm 23.49$ & $91.12 \pm 4.35$ & $92.80 \pm 10.97$ \\
\hline
\end{tabular}

Results are expressed as the mean $\pm \mathrm{SD}$. *Significantly different at $p<0.05$ from the pre-irradiation mean based on results from $t$-tests.

Table II. Results of dark-adapted electroretinography before and after light exposure.

\begin{tabular}{|c|c|c|c|c|c|}
\hline Parameter & Test & Pre-irradiation & $24 \mathrm{~h}$ after & 7 days after & 14 days after \\
\hline \multirow[t]{3}{*}{ a-Wave implicit time (ms) } & 1 & $10.86 \pm 0.24$ & $10.76 \pm 0.43$ & $11.5 \pm 0.43 *$ & $11.84 \pm 2.73$ \\
\hline & 2 & $10.74 \pm 0.10$ & $9.82 \pm 0.88$ & $9.42 \pm 0.48 *$ & $9.6 \pm 0.66^{*}$ \\
\hline & 4 & $8.32 \pm 0.23$ & $7.14 \pm 1.06$ & $6.56 \pm 0.66^{*}$ & $6.82 \pm 0.58 *$ \\
\hline \multirow[t]{3}{*}{ b-Wave implicit time (ms) } & 1 & $43.98 \pm 0.95$ & $50.28 \pm 13.84$ & $39.28 \pm 3.21 *$ & $42.22 \pm 8.63$ \\
\hline & 2 & $34.12 \pm 0.56$ & $35.62 \pm 2.34$ & $35.28 \pm 2.92$ & $52.8 \pm 9.76^{*}$ \\
\hline & 4 & $39.92 \pm 3.63$ & $42.24 \pm 6.99$ & $42.24 \pm 4.16$ & $42.02 \pm 2.82$ \\
\hline \multirow[t]{3}{*}{ a-Wave amplitude $(\mu \mathrm{V})$} & 1 & $-12.58 \pm 2.30$ & $-10.5 \pm 2.03$ & $-9.52 \pm 3.11$ & $-12.54 \pm 6.27$ \\
\hline & 2 & $-90.28 \pm 23.52$ & $-106.26 \pm 15.32$ & $-123.08 \pm 25.97$ & $-145 \pm 19.32 *$ \\
\hline & 4 & $-141.4 \pm 14.36$ & $-143.2 \pm 9.99$ & $-147.4 \pm 23.79$ & $-167 \pm 14.34^{*}$ \\
\hline \multirow{3}{*}{ b-Wave amplitude $(\mu \mathrm{V})$} & 1 & $163.2 \pm 20.27$ & $170.2 \pm 35.55$ & $190.6 \pm 33.21$ & $180.4 \pm 31.59$ \\
\hline & 2 & $178.4 \pm 31.13$ & $209.4 \pm 22.31$ & $221.4 \pm 63.95$ & $229.8 \pm 42.23$ \\
\hline & 4 & $228.6 \pm 36.42$ & $242.4 \pm 29.34$ & $260.2 \pm 64.35$ & $278.8 \pm 56.09$ \\
\hline Summed implicit time $(\mathrm{ms})$ & 3 & $143.9 \pm 0.85$ & $130.68 \pm 21.80$ & $141.4 \pm 3.37$ & $114.32 \pm 6.32 *$ \\
\hline Summed amplitude $(\mu \mathrm{V})$ & 3 & $100.66 \pm 9.80$ & $126.4 \pm 12.63 *$ & $104.66 \pm 15.25$ & $147.5 \pm 36.03 *$ \\
\hline
\end{tabular}

Results are expressed as the mean $\pm \mathrm{SD}$. *Significantly different at $p<0.05$ from the pre-irradiation mean based on results from $t$-tests.

Electroretinography $(E R G)$. The results of ERG are summarized in Table I and Table II. In the light-adapted test 1, which provided an overall assessment of the outer and inner retina during day vision. The light irradiation caused significant $(p<0.001)$ reductions in both a- and b-wave amplitudes to $77.6 \%$ and $65.6 \%$ of the pre-irradiation value immediately after light irradiation, respectively (Figure 3A and B). Significant $(p<0.001)$ increases in both $\mathrm{a}$ - and $\mathrm{b}$-wave amplitudes to $158.2 \%$ and $127.6 \%$ of the pre-irradiation values were measured $30 \mathrm{~min}$ after light irradiation. After that, they recovered to the pre-irradiation values within $24 \mathrm{~h}$. In the light-adapted test 2 (light-adapted 8.0 flicker, $28.3 \mathrm{~Hz}$ ), the amplitudes of the bwaves were $82.78 \mu \mathrm{V}$ before light irradiation. A significant $(p<0.05)$ reduction to $88.11 \%$ of the pre-irradiation value was measured immediately after light irradiation (Figure 3C); after $30 \mathrm{~min}$, there was no significant difference from the preirradiation value. The implicit durations shown by the lightadapted ERG tended to decrease immediately after light irradiation and recovered over time, but it was not always statistically significant.
In the dark-adapted test 2 , which provided a mixed assessment of rods and cones during night vision, the amplitudes of the a- and b-waves tended to increase $24 \mathrm{~h}$ after light irradiation; however, the change was not statistically significant.

Histological analysis. No histopathological signs of retinal damage were observed during the histological study of the controls and experimental eyes at 1, 7, and 14 days after irradiation (Figure 4). No pyknotic nuclei, apoptotic bodies of photoreceptors, retinal detachment from retinal pigment epithelium, and phagocytosis of apoptotic bodies by retinal pigment epithelium cells (RPE cells) were observed. Other signs, including gliosis, activation of RPE cells, glial scar formation, newly formed canals filled with edematous fluid, muller glial activation and hypertrophy, and inflammatory cells between the photoreceptor layer and RPE, were also not observed. There were no significant differences in the thickness of the ONL between the control and lightirradiated groups (Figure 5). 
A

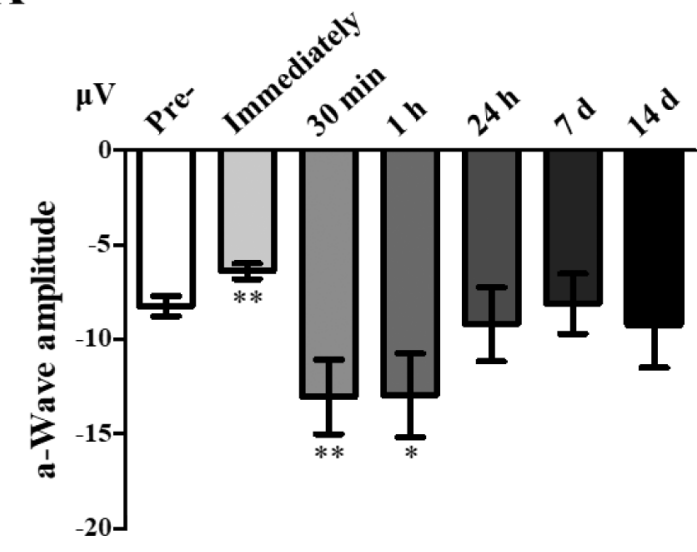

B

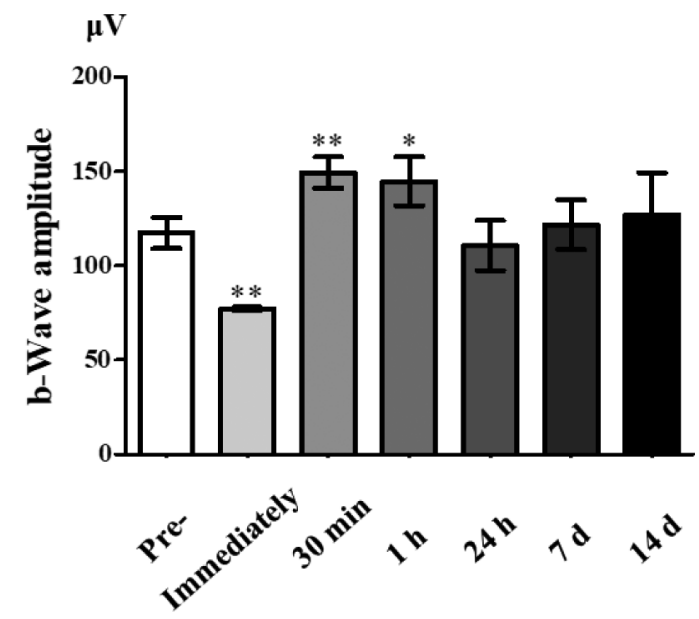

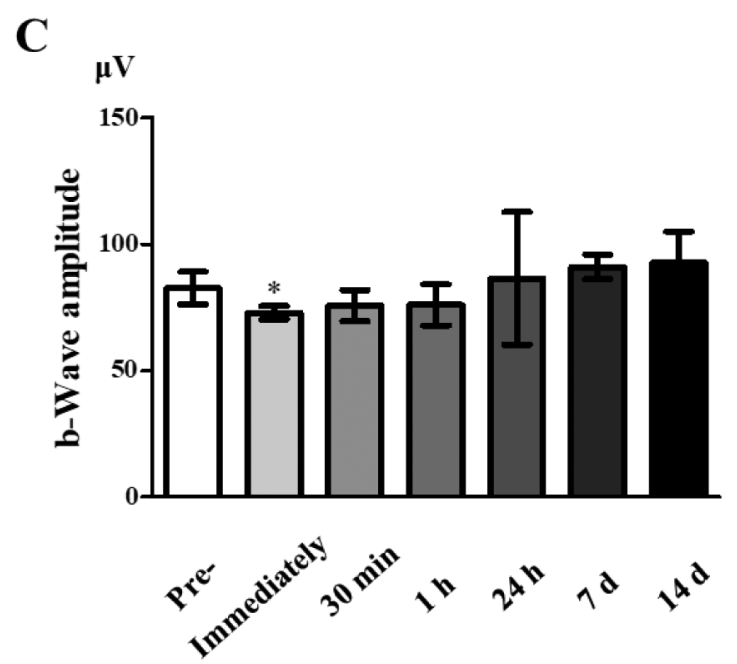

Figure 3. Light-adapted electroretinography amplitudes in rabbits before and after light exposure. (A) The a-wave amplitude in light-adapted test 1. (B) The b-wave amplitude in light-adapted test 1. (C) The b-wave amplitude in light-adapted test 2 . Statistically significant decrements were measured immediately after light irradiation. Pre-: Pre-irradiation. Results are expressed as the mean \pm SD. Significantly different at $* p<0.05$ and $* * p<0.001$ versus pre-irradiation.

\section{Discussion}

Several experiments have been conducted to study retinal toxicity using various light sources $(2,11-14)$. Various clinical findings and histological results have been reported, ranging from reversible damage to extensive and permanent retinal damage, depending on the intensity and the duration of exposure to the light source $(2,11-14)$. Therefore, the light source's intensity and duration of exposure associated with visual paralysis were selected as the parameters for irradiation in assessing retinal damage. The experimental results showed no abnormal findings in the cornea, iris, conjunctiva, and aqueous humor on slit-lamp biomicroscopy before and 1, 7, and 14 days after light irradiation. Conjunctival hyperemia and swelling were observed in one animal 1 day after light irradiation, but they were attributed to the stimulation by a contact lens type electrode when the ERG test device was placed or the hydroxypropyl methylcellulose gel used during installation (15).

The retinal ERG was carried out after dark adaptation and light adaptation. The functioning of rod cells, predominantly responsible for night vision, was mainly evaluated using darkadapted ERG. The cone cell function, mostly responsible for daytime vision, was assessed using light-adapted ERG. However, the contributions of rods and cones to vision depend on the intensity of light and its frequency, and the functions of 


\section{Control}

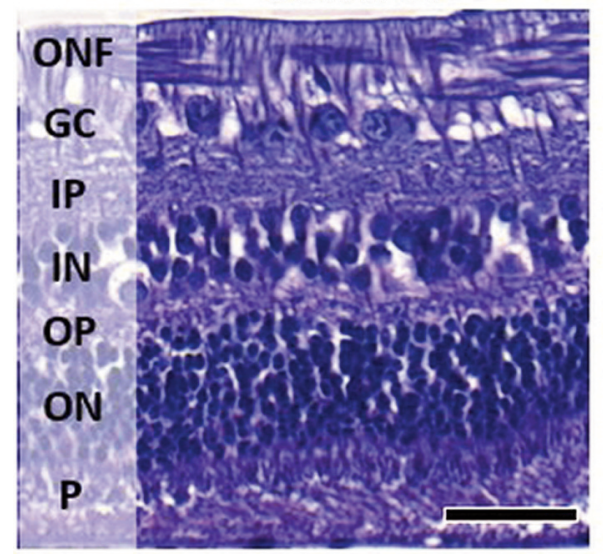

Day 7

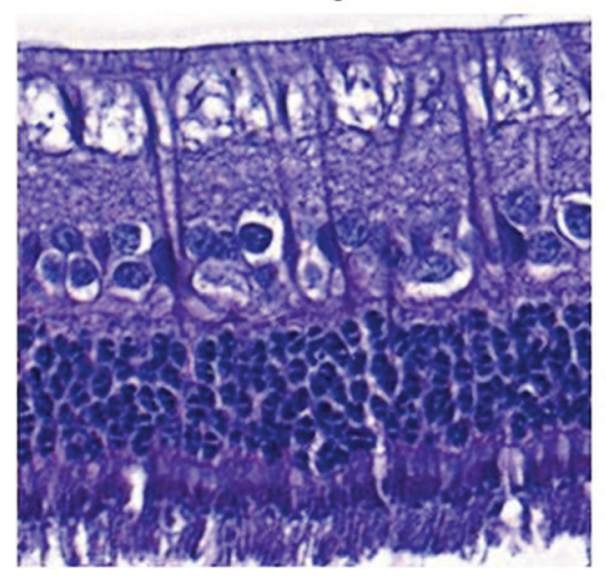

\section{Day 1}

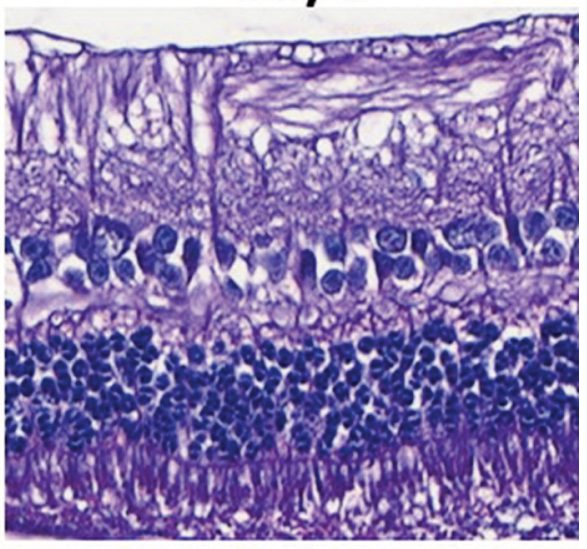

Day 14

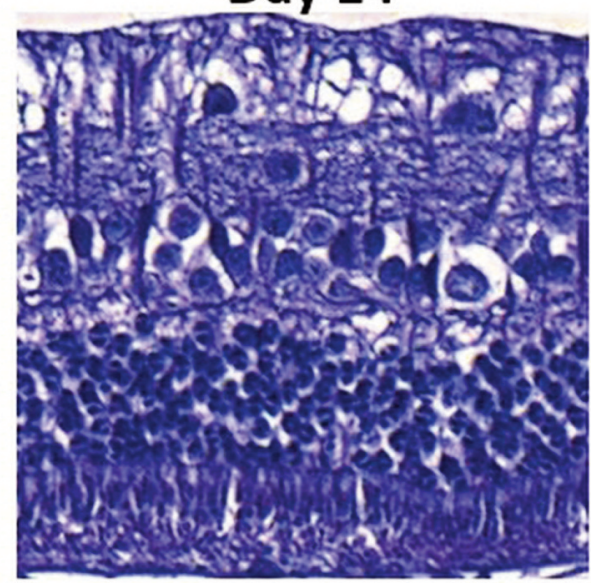

Figure 4. Histopathological evaluations of the light-irradiated retina on retinal cross-sections. No histopathological signs of retinal damage were observed during the histological study of the controls and groups at 1, 7 and 14 days after irradiation (Scale bar: $25 \mu \mathrm{m}$ ). ONF: Optic nerve fiber layer; GC: ganglion cell layer; IP: inner plexiform layer; IN: inner nuclear layer; OP: outer plexiform layer; ON: outer nuclear layer; P: photoreceptor layer.

the two types of cell cannot be completely separated and evaluated. Therefore, the evaluation was performed comprehensively using ERG under various conditions $(16,17)$.

The light-adapted ERG showed a significant decrease in amplitudes of both waveforms immediately after irradiation. During the light-adapted test 1 , the amplitude decreased immediately after irradiation, and a significant increase was observed $30 \mathrm{~min}$ and $1 \mathrm{~h}$ after irradiation. Moreover, amplitudes recovered $24 \mathrm{~h}$ after irradiation. As the darkadapted state of the retina is not maintained after light irradiation, the dark-adapted ERG was performed immediately, and 1,7 , and 14 days after irradiation. All the tests showed no significant amplitude reduction or implicit time delay which was indicative of retinal damage. Instead, during the darkadapted tests 2,3 , and 4 , the amplitude increased immediately through 14 days after irradiation. In other words, it was confirmed that short-term exposure to bright light did not affect normal night vision based on the ERG results. The visual function was temporarily affected immediately after irradiation for day vision, but color recognition recovered within $30 \mathrm{~min}$. It was also confirmed that both contrast and color recognition were restored within $24 \mathrm{~h}$.

The increase in the ERG wave amplitude after light irradiation can be regarded as the temporary activation of photoreceptors. The mechanism by which amplitude temporarily decreases and increases is unknown, and it cannot be considered that this change leads to activation of visual function. As a result, no complete ERG waveform was lost enough to affect vision after light irradiation; after approximately $10-30 \%$ reduction, the amplitude was 


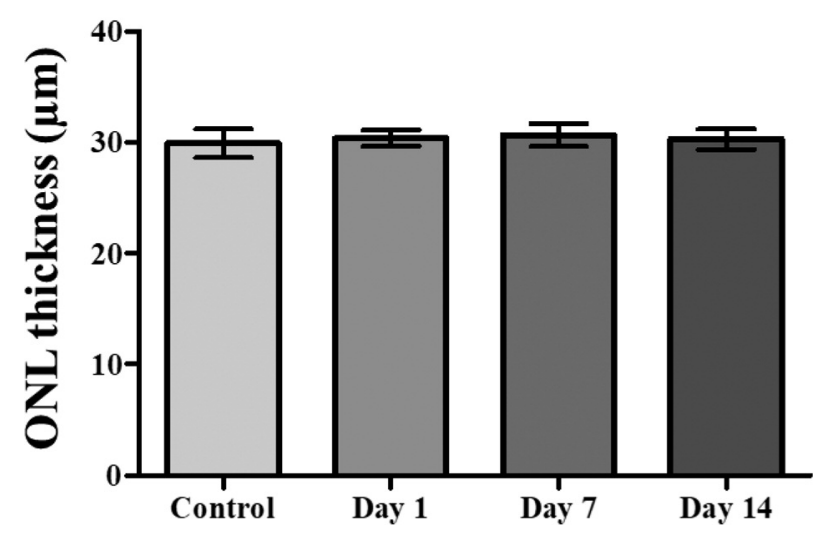

Figure 5. Comparison of the thickness of the outer nuclear layer (ONL) of the retina of the controls and light-irradiated groups. Results are expressed as the mean $\pm S D$. There were no significant differences between the irradiated groups and the controls.

restored within $24 \mathrm{~h}$. Thus, it may be concluded that the self-defense product temporarily affects vision but vision recovers within $24 \mathrm{~h}$.

Animal models for retinal phototoxicity have been used in several studies. Light-induced damage in nocturnal rats was shown to induce damage of retinal cells and rod cells, mostly limited to the ONL $(3,18-20)$. Even in rabbits, the thickness of the ONL decreases when there is damage to the retina by light. The initial process of retinal damage is a rapid increase in lipid peroxidation, which destroys cells in the retina and photoreceptors via apoptosis. If oxidative damage is not severe, the cells remain alive but damaged, with vacuolated outer segments. Antioxidant efforts are made in the cell itself, but the damage continues its course, and gradual destruction causes a large reduction in ONL thickness $(7,10$, 19). In this experiment, after irradiating the rabbit's eye with short-term bright light, the thickness of the ONL did not show any significant change over time compared with the control group. According to several studies, various characteristics of retinal degeneration can be observed in retinal tissues after exposure to light in experimental animals (21-27). In this study, the histological analysis showed no specific findings within 1,7 and 14 days after exposure to short-term bright light.

This study confirmed that when short-term bright light from a self-defense product was irradiated into the rabbit's eye, the visual function recovered within $24 \mathrm{~h}$, and no structural damage or histological changes occurred. No further changes in the ERG waveform and histopathological results were observed up to the second week after visual function had recovered (within $24 \mathrm{~h}$ ). This indicates that no further damage was caused after temporary visual paralysis. However, as the degree of damage varies with the exposure conditions, it may change depending on the exposure time, source distance, or the intensity of the light source.

\section{Conflicts of Interest}

The Authors have no financial conflicts of interest.

\section{Authors' Contributions}

H Park, K Jang, KM Shim and SE Kim designed the study concept. H Park and Y Jo collected and analyzed the data. H Park and K Jang wrote the whole article. KM Shim and C Bae critically revised the article. SE Kim and SS Kang supervised the study. All Authors read and approved the final version of the article.

\section{Acknowledgements}

This research was supported by the Basic Science Research Program through the National Research Foundation of Korea (NRF) funded by the Ministry of Education (NRF-2020R1C1C1009798). The Authors thank the Ophthalmic Optic Medical Device Globalization Team and Newseogwang Co. for their assistance.

\section{References}

1 Aydin B, Dinç E, Yilmaz SN, Altiparmak UE, Yülek F, Ertekin S, Yilmaz M and Yakın M: Retinal endoilluminator toxicity of xenon and light-emitting diode (LED) light source: rabbit model. Cutan Ocul Toxicol 33(3): 192-196, 2014. PMID: 24147949. DOI: $10.3109 / 15569527.2013 .832282$

2 Ramirez J, Meyer U, Stoppa M and Wenzel M: Electrophysiological and morphological changes in rabbit retina after exposure to the light of the operating microscope. Graefes Arch Clin Exp Ophthalmol 230(4): 380-384, 1992. PMID: 1505773. DOI: 10.1007/BF00165950

3 Krigel A, Berdugo M, Picard E, Levy-Boukris R, Jaadane I, Jonet L, Dernigoghossian M, Andrieu-Soler C, Torriglia A and BeharCohen F: Light-induced retinal damage using different light sources, protocols and rat strains reveals LED phototoxicity. Neuroscience 339: 296-307, 2016. PMID: 27751961. DOI: 10.1016/j.neuroscience.2016.10.015

4 Lee J, Kim H and Cho H: Retinal changes in white rabbits after exposure to the light of an operating microscope. Journal of the Korean Ophthalmological Society 52(5): 603, 2021. DOI: 10.3341/jkos.2011.52.5.603

$5 \mathrm{Wu}$ J, Seregard S and Algvere PV: Photochemical damage of the retina. Surv Ophthalmol 51(5): 461-481, 2006. PMID: 16950247. DOI: 10.1016/j.survophthal.2006.06.009

6 Clarke AM, Geeraets WJ and Ham WT Jr: An equilibrium thermal model for retinal injury from optical sources. Appl Opt 8(5): 1051-1054, 1969. PMID: 20072372. DOI: 10.1364/ AO.8.001051

7 Organisciak DT and Vaughan DK: Retinal light damage: mechanisms and protection. Prog Retin Eye Res 29(2): 113-134, 2010. PMID: 19951742. DOI: 10.1016/j.preteyeres.2009.11.004

8 Foote CS: Mechanisms of photosensitized oxidation. There are several different types of photosensitized oxidation which may be important in biological systems. Science 162(3857): 963-970, 1968. PMID: 4972417. DOI: 10.1126/science.162.3857.963 
9 Korycka-dahl M and Richardson T: Photogeneration of superoxide anion in serum of bovine milk and in model systems containing riboflavin and amino acids. Journal of Dairy Science 61(4): 400407, 2021. DOI: 10.3168/jds.S0022-0302(78)83613-3

10 Saenz-de-Viteri M, Heras-Mulero H, Fernández-Robredo P, Recalde S, Hernández M, Reiter N, Moreno-Orduña M and GarcíaLayana A: Oxidative stress and histological changes in a model of retinal phototoxicity in rabbits. Oxid Med Cell Longev 2014: 637137, 2014. PMID: 24991304. DOI: $10.1155 / 2014 / 637137$

11 Yoon HM, Jang Y, Kim JS and Ji NC: An ultrastructural study of recovery of photoreceptor layer from visible light-induced damage. J Korean Ophthalmol Soc 34(7): 678-686, 1993.

12 Hochheimer BF, D'Anna SA and Calkins JL: Retinal damage from light. Am J Ophthalmol 88(6): 1039-1044, 1979. PMID: 117713. DOI: $10.1016 / 0002-9394(79) 90413-6$

13 Lawwill T: Three major pathologic processes caused by light in the primate retina: a search for mechanisms. Trans Am Ophthalmol Soc 80: 517-579, 1982. PMID: 6763803.

14 Wiegand RD, Giusto NM, Rapp LM and Anderson RE: Evidence for rod outer segment lipid peroxidation following constant illumination of the rat retina. Invest Ophthalmol Vis Sci 24(10): 1433-1435, 1983. PMID: 6618806.

15 Connolly $M$ and Buckley DA: Contact dermatitis from propylene glycol in ECG electrodes, complicated by medicament allergy. Contact Dermatitis 50(1): 42, 2004. PMID: 15059104. DOI: $10.1111 / \mathrm{j} .0105-1873.2004 .00271 \mathrm{c} . \mathrm{x}$

16 McCulloch DL, Marmor MF, Brigell MG, Hamilton R, Holder GE, Tzekov R and Bach M: ISCEV Standard for full-field clinical electroretinography (2015 update). Doc Ophthalmol 130(1): 1-12, 2015. PMID: 25502644. DOI: 10.1007/s10633014-9473-7

17 Gjörloff K, Andréasson S and Ehinger B: Standardized full-field electroretinography in rabbits. Doc Ophthalmol 109(2): 163-168, 2004. PMID: 15881262. DOI: 10.1007/s10633-004-3924-5

18 Narimatsu T, Ozawa Y, Miyake S, Kubota S, Yuki K, Nagai N and Tsubota $\mathrm{K}$ : Biological effects of blocking blue and other visible light on the mouse retina. Clin Exp Ophthalmol 42(6): 555-563, 2014. PMID: 24304494. DOI: 10.1111/ceo.12253

19 Tanito M, Kaidzu S and Anderson RE: Protective effects of soft acrylic yellow filter against blue light-induced retinal damage in rats. Exp Eye Res 83(6): 1493-1504, 2006. PMID: 16997296. DOI: $10.1016 /$ j.exer.2006.08.006

20 Tanito M, Kaidzu S and Anderson RE: Delayed loss of cone and remaining rod photoreceptor cells due to impairment of choroidal circulation after acute light exposure in rats. Invest Ophthalmol Vis Sci 48(4): 1864-1872, 2007. PMID: 17389522. DOI: 10.1167 /iovs.06-1065
21 Baksheeva VE, Tiulina VV, Tikhomirova NK, Gancharova OS, Komarov SV, Philippov PP, Zamyatnin AA Jr, Senin II and Zernii EY: Suppression of light-induced oxidative stress in the retina by mitochondria-targeted antioxidant. Antioxidants (Basel) 8(1): 3, 2018. PMID: 30577635. DOI: 10.3390/antiox8010003

22 Zernii EY, Nazipova AA, Gancharova OS, Kazakov AS, Serebryakova MV, Zinchenko DV, Tikhomirova NK, Senin II, Philippov PP, Permyakov EA and Permyakov SE: Light-induced disulfide dimerization of recoverin under ex vivo and in vivo conditions. Free Radic Biol Med 83: 283-295, 2015. PMID: 25772009. DOI: 10.1016/j.freeradbiomed.2015.03.001

23 Zernii EY, Nazipova AA, Nemashkalova EL, Kazakov AS, Gancharova OS, Serebryakova MV, Tikhomirova NK, Baksheeva VE, Vladimirov VI, Zinchenko DV, Philippov PP, Senin II and Permyakov SE: Light-induced thiol oxidation of recoverin affects rhodopsin desensitization. Front Mol Neurosci 11: 474, 2019. PMID: 30666186. DOI: 10.3389/fnmol.2018.00474

24 Novikova YP, Gancharova OS, Eichler OV, Philippov PP and Grigoryan EN: Preventive and therapeutic effects of SkQ1containing Visomitin eye drops against light-induced retinal degeneration. Biochemistry (Mosc) 79(10): 1101-1110, 2014. PMID: 25519068. DOI: 10.1134/S0006297914100113

25 Zarbin MA, Casaroli-Marano RP and Rosenfeld PJ: Age-related macular degeneration: clinical findings, histopathology and imaging techniques. Dev Ophthalmol 53: 1-32, 2014. PMID: 24732758. DOI: 10.1159/000358536

26 Yorston D: What's new in age-related macular degeneration? Community Eye Health 19(57): 4-5, 2006. PMID: 17491733.

27 el Baba F, Jarrett WH 2nd, Harbin TS Jr, Fine SL, Michels RG, Schachat AP and Green WR: Massive hemorrhage complicating age-related macular degeneration. Clinicopathologic correlation and role of anticoagulants. Ophthalmology 93(12): 1581-1592, 1986. PMID: 2433658. DOI: 10.1016/s0161-6420(86)33540-1

Received October 22, 2021

Revised November 17, 2021

Accepted December 1, 2021 